Peripheral Arterial Disease, a Physician's Approach

By Robert L. Richards. Pp. 126, illustrated. Edinburgh and London: E. \& S. Livingstone, 1970. $£ 210$ s.

As the author states in his preface there has been no worthy successor to Sir Thomas Lewis's 'Vascular Disorders of the Limbs', first published in 1936. The lack of such a work has long been apparent to physicians, and has now been remedied in a really masterly manner.

This short book commences with the history of the subject, anatomy and physiology of the normal peripheral circulation, before proceeding to the classification of arterial disease. Each section is presented slearly and concisely, with excellent illustrations. Subsequent chapters deal with symptoms, signs and special investigations; and then with specific syndromes including claudication, acute and chronic ischaemia, and Raynaud's syndrome. Aetiology, medical and surgical therapy are discussed most adequately and like the whole work are presented in a refreshingly clear fashion. For those who wish to pursue in greater depth, a fourteen page bibliography provides ample coverage of the literature.

At a time when a deluge of new books is upon us, it is a delight to find one filling so obvious a gap with such an excellent presentation. I am sure that this slim volume should be on the shelves of all interested physicians and vascular surgeons.

\section{Electrophysiology of Pacing and Cardioversion}

By Augustin Castellanos and Louis Lemberg. Pp. 250, illustrated. London: Butterworths; New York: AppletonCentury Crofts, $1969 . £ 5$.

This is a highly specialized book that will be of most interest to specialists in Electrocardiography, especially those interested in dysrhythmias, and those responsible for a considerable amount of defibrillation, pacemaker insertion and supervision. For those with fewer demands of this nature, Siddon's and Sowton's 'Cardiac Pacemakers' provides all the necessary information on the pacing aspect. The present book should also be read by Electrophysiologists as the authors have taken advantage of pacemaker induced ECG patterns to study this subject in some depth, including observations on excitability, automaticity and conduction times.

Each chapter is followed by an excellent selection of ECGs illustrating the text and these are in turn accompanied by detailed interpretation. The selection of 'Iatrogenic arrhythmias' is particularly comprehensive.

Although destined to this rather specialized audience this work can be thoroughly recommended to those concerned.

\section{Preventive Medicine in Medical Care}

By Kurt Schwarz. Pp. $x+216$. London: H. K. Lewis, 1970. £2 10s.

Preventive medicine does not receive the attention it deserves in what is euphemistically called the National Health Service and tends to be somewhat neglected in the overcrowded curriculum of the medical schools. This book attempts to cover the practice of preventive medicine in its broadest context and seeks to offer perspectives in priorities for medical planning, for the promotion of community health and for the prevention and control of specific disorders.

The clinical features described are too brief to be helpful and contain some statements which are inaccurate e.g. In $60 \%$ of cases of measles Koplik spots 'accompany or even follow the onset of the main rash', and others which are somewhat misleading and one can only assume that the author is not practising clinical medicine. Attention is given to primary prevention which assumes some importance in the non-infectious diseases but in the context of infectious diseases is of more theoretical than practical value. Each chapter follows a uniform arrangement and considers the interesting problem of presymptomatic diagnosis. This, together with epidemiology, secondary prevention and public health aspects, constitutes the more valuable sections of the book.

This is an ambitious book and the concept is admirable but in attempting so much within the confines of a few pages one regrets to say that it fails to achieve its objective. The author states that the book is intended for senior undergraduate students as well as postgraduates but the former, without prior knowledge of the subject, would be unable to sift out the wheat from the chaff. Inevitably also the subject matter is not considered in sufficient depth for the postgraduate although helpful in encouraging a different approach to present-day problems in medicine.

\section{Manual of Clinical Microbiology}

Edited by J. E. Blair, E. H. Lennette and J. P. Truant. Pp. 727, illustrated. Baltimore, Maryland: Williams and Wilkins; Edinburgh and London: E. \& S. Livingstone, 1970. $£ 3$ ss.

It is very difficult to produce a book which, at one and the same time, is easily readable, informative to the non-teohnical reader seeking guidance on the interpretation of results and fully instructive to the technician performing bacteriological and serological tests. In the reviewer's opinion, this has been achieved in this book. The work contains seventy-six chapters written by sixty-five authors each of whom is clearly an authority in his subject both theoretically and technically. The authors do not disguise the fact that problems of identification of organisms or interpretation of results occur frequently. They indicate clearly what further tests are and are not practical in a routine laboratory.

The book includes sections or chapters dealing very adequately with all bacteriological and serological procedures and includes the identification of parasites, the identification of viruses and rickettsiae, bacteria phage typing, environmental control in hospitals and food poisoning.

The reader requiring further information is provided with copious references which the reviewer was pleased to see included the title of the paper. The formula for all reagents mentioned, including buffers, is given in the text or in the final section on 'Media and Reagents'. This is a great convenience.

This book deserves to be very popular but it is to be hoped that the spelling of 'diptheriae' (sic) on page 90 lines 23 and 41 and of 'diptheroids' (sic) on page 96 line 46 will be corrected in the next edition.

\section{Textbook of Contraceptive Practice}

By John Peel and Malcolm Potts. Pp. 296, illustrated. London: Cambridge University Press, 1969. £2 10. 18s (Paperback).

Although the first contraceptive clinic in Britain was opened close on 50 years ago, contraception has only recently become 'respectable' national policy and the opening of new Family Planning Association headquarters accorded royal patronage. And similarly since the teaching of contraceptive techniques was not an integral part of the curriculum, textbooks on the subject have been lacking. This book fills a gap and is suitable both for undergraduate and postgraduate students.

Unlike many textbooks, however, it is eminently readable and the intelligent layman would find many sections, and especially the historical aspects, of interest. The different contraceptive methods are clearly described and criteria for their 
standards and specifications discussed. Physiological mechanisms are well summarized; the diagrams are clear. The description of abortion techniques is perhaps out of place since such operations should be performed only by those fully instructed and experienced in the procedures and for this purpose more detail would, in any care, be required. But this is a minor criticism. Overall, the book is to be recommended and the price of the paperback edition ( 18 shillings), refreshingly reasonable.

\section{Serotonin}

By I. H. Page. Pp. 143. Chicago: Year Book Medical Publishers; Chichester: John Wiley, 1969. £3 15s.

The author was one of the discoverers of serotonin more than twenty years ago, and he has continued to make important contributions in this field. This book bears the imprint of his close personal involvement. As the Preface and Introduction tell us, it was written not as a comprchensive review, but to express a point of view. Dr Page has thus reserved the right to include and exclude material with a free hand, and this he has clearly done. It is likely that the book will be most profitably read by those who are sufficiently interested in serotonin to have points of view of their own.

The generous tributes to other workers are a pleasing feature of the book. An exception to this is the disapproval of the 'stark and forlorn' 5HT (short for 5-hydroxytryptamine) introduced by the late Sir John Gaddum in lieu of the author's 'mellifluous and warm' serotonin. However, serotonin appears rather a restrictive term in view of the many biological roles attributed to it. Those listed in the concluding final 'overview' include transmitter functions in the nervous system, regulation of gastrointestinal motility and of cardiovascular functions, pineal control of rhythmic activities, influence on the body temperature, and effects on the carbohydrate metabolism in invertebrates. Even more varied is the involvement of serotonin in pathological processes. In addition to its established role in inflammatory conditions, carcinoid and dumping syndromes, serotonin is being studied in migraine, Down's syndrome, rheumatic diseases, and as a teratogenic agent.

Dr Page writes with gusto and in a colourful style. As he says, 'the book has been written to be read, and in a short time at that!'

\section{The Surgical Management of Ulcerative Colitis}

By F. C. Walker. Pp. 147, illustrated. London: Butterworth, 1969. £2 10s.

In the preface the author states that this book is an attempt to present the experiences which have emerged from the treatment of about $4 \mathrm{CO}$ patients afflcted with ulcerative colitis. He has done this most admirably in eight chapters. The first is an introduction dealing briefly with clinical, pathological and etiological features of the disease and the second and third chapters deal with the diagnosis and the complications respectively. The fourth chapter mentions the indications for surgery and choice of operation and the remaining four chapters deal with the operation, the ileostomy, ileostomy dysfunction and the cost of colectomy. At the end of all the chapters there are useful references.

This book makes absorbing and enjoyable reading. It would prove useful to the postgraduate trainee surgeon and to all the nurses who have to deal with the unfortunate sufferers in the managemen $i$ of such things as ileostomy, prolapse, recession, skin excoriation and the techniques of fitting the various appliances.

Professor D. N. Walder in writing the foreword states that the author, by his understanding, knowledge and devoted care, has helped to rehabilitate the unfortunate patients who have been demoralized by a life dominated by the nearest WC and has thus become their friend. After reading the book and particularly after looking at the photograph of a group of happy patients on page 129 , I would like to echo Professor Walder's sentiments.

This book can be thoroughly recommended to all who have to deal with unfortunate sufferers of the disease. 